\title{
O Desenvolvimento da Escrita nos Anos Pré-Escolares: Questões Acerca do Estágio Silábico ${ }^{1}$
}

\author{
Cláudia Cardoso-Martins ${ }^{2}$ \\ Marcela Fulanete Corrêa \\ Universidade Federal de Minas Gerais
}

\begin{abstract}
RESUMO - O presente estudo investiga a evolução da escrita em uma amostra de 20 crianças em idade pré-escolar. A habilidade de escrever palavras foi avaliada de seis em seis meses, por um período de aproximadamente dois anos. No início do estudo, as crianças tinham, em média, 4 anos e 6 meses de idade e nenhuma havia começado a ler ou a escrever. Ao final do estudo, por outro lado, com exceção de uma criança, todas podiam escrever alfabeticamente. Os resultados sugerem que o modelo de fases de Ehri fornece uma descrição mais apropriada do desenvolvimento inicial da escrita de crianças falantes do português brasileiro do que o modelo de estágios de Ferreiro.
\end{abstract}

Palavras-chave: desenvolvimento da escrita; conhecimento das letras; estágio silábico.

\section{The Development of Spelling Skills in the Preschool Years: Questions about the Syllabic Stage}

\begin{abstract}
The present study investigates spelling development in a sample of 20 preschool children. Spelling skills were evaluated every six months, for a period of approximately 24 months. At the beginning of the study, the children were, on average, 4.6 years old, and none had started to read or spell. By the end of the study, on the other hand, all but one child could spell alphabetically. Results suggest that Ehri's phase model offers a more appropriate account of spelling development by Brazilian Portuguese-speaking children than Ferreiro's stage model.
\end{abstract}

Key words: spelling development; letter knowledge; syllabic stage.

Dois paradigmas principais têm influenciado os estudos sobre o desenvolvimento da escrita: o paradigma construtivista e o paradigma fonológico. O paradigma construtivista baseia-se no pressuposto de que o desenvolvimento da escrita é, em grande parte, determinado por mudanças na capacidade lógica da criança. A pesquisa influenciada por esse paradigma tem, por conseguinte, procurado descrever as hipóteses que a criança constrói sobre a natureza da escrita ao longo dos anos pré-escolares e início dos anos escolares. O paradigma fonológico, por outro lado, baseia-se no pressuposto de que a principal tarefa da criança ao aprender a ler e escrever consiste em compreender que as letras representam sons na pronúncia das palavras. Como resultado, esse paradigma tem estimulado estudos sobre a relação entre o desenvolvimento do conhecimento das correspondências letra-som e da consciência fonológica, por um lado, e o desenvolvimento da escrita, por outro lado.

O paradigma construtivista, sobretudo os trabalhos de Emilia Ferreiro, tem tido um profundo impacto no conceito da alfabetização no Brasil (Comissão de Educação e Cultura da Câmara dos Deputados, 2003). Em uma série de trabalhos, Ferreiro (1989, 1990; Ferreiro \& Gomez Palacio, 1982; Ferreiro \& Teberosky, 1986) tem argumentado que o desenvolvimento da escrita é o resultado de um longo processo de construção

1 Agradecimentos: Este trabalho foi possível graças a um financiamento do Conselho de Desenvolvimento Científico e Tecnológico, CNPq. Agradecemos às crianças e aos seus professores pela sua colaboração.

2 Endereço: Departamento de Psicologia, Universidade Federal de Minas Gerais, Av. Antônio Carlos, 6627, Pampulha, Belo Horizonte, MG, Brasil 31270-901. E-mail: cacau@fafich.ufmg.br conceitual, o qual pode ser descrito em termos de três estágios ou períodos principais. No Brasil (e.g., Grossi, 1990; Pimentel, 1986; Silva \& Farias, 2003), esses estágios são frequentemente denominados de pré-silábico, silábico e alfabético.

No estágio pré-silábico, a criança ainda é alheia ao fato de que a escrita representa os sons da fala. No entanto, ela já compreende a natureza simbólica da escrita e dedica um grande esforço intelectual na definição das suas características distintivas. São desse estágio dois dos princípios mais famosos de Ferreiro: o princípio da quantidade mínima e o princípio de variações qualitativas. De acordo com o primeiro, uma grafia deve conter um número mínimo de letras que é, em geral, três. Mas não é suficiente que uma representação gráfica tenha três letras para se qualificar como uma palavra. Uma grafia deve também obedecer ao princípio de variações qualitativas, ou seja, deve ser constituída por letras diferentes.

Tendo elaborado esses princípios, a criança volta a sua atenção para a construção de critérios de diferenciação entre escritas diferentes. Segundo Ferreiro, a busca por esses critérios dá origem a uma verdadeira revolução conceitual - a compreensão de que os sinais gráficos ou letras representam segmentos sonoros na fala. Inicialmente, contudo, a criança acredita que as letras representam segmentos silábicos na pronúncia da palavra. Como consequiência, escreve uma e apenas uma letra para cada sílaba na palavra, produzindo, por exemplo, a sequiência de letras XYS para a palavra caballo "cavalo" (Ferreiro \& Gomez Palacio, 1982). Essa hipótese, denominada hipótese silábica, é desestabilizada pelo confronto com a escrita do meio ambiente e, eventualmente, cede lugar para a hipótese alfabética. No está- 
gio alfabético, as letras passam a ser concebidas como o que elas de fato são: símbolos visuais que representam fonemas. Desse modo, as escritas da criança passam a ser organizadas em termos das correspondências entre as letras e os sons, assemelhando-se, portanto, à escrita convencional.

De acordo com Ferreiro, as escritas silábicas representam um marco extremamente importante no desenvolvimento da escrita. Além de constituir a primeira manifestação da compreensão infantil de que a escrita representa a fala, a hipótese silábica chama a atenção da criança para as semelhanças e diferenças sonoras entre as palavras (Ferreiro, 1989). Como resultado, mais cedo ou mais tarde, a criança começa a explorar a hipótese de que as letras representam valores sonoros relativamente estáveis. Uma vez que em espanhol a representação das vogais é muito regular, é comum que as crianças façam uso da mesma vogal para representar sílabas diferentes que contenham o mesmo som vocálico. Por exemplo, Ferreiro (1989) cita o caso de uma criança que escreveu AIOA para mariposa, AAO para pajaro "pássaro", $A O A$ para paloma "pomba" e, finalmente, $A O$ para gato. Como esses exemplos sugerem, a criança aparentemente usou as letras $A$ e $O$ para representar sílabas que continham os sons /a/ e /o/, respectivamente.

Cardoso-Martins e Batista (2005) apresentaram uma revisão radical da teoria de Ferreiro. Em particular, essas pesquisadoras sugeriram que a escrita silábica resulta, em grande parte, da tentativa da criança de escrever as letras cujo som ela é capaz de detectar na pronúncia das palavras. Em espanhol - e isso também é verdade para outras línguas em que a escrita silábica tem sido documentada como, por exemplo, o português (Grossi, 1990; Pimentel, 1986; Silva \& Farias, 2003) e o italiano (Pontecorvo \& Zucchermaglio, 1990) - esses sons correspondem com freqüência às vogais, cujos nomes são freqüentemente escutados na pronúncia das palavras. Como por definição só existe uma vogal por sílaba, a escrita da criança em idade pré-escolar que conhece o nome das letras será algumas vezes silábica. Em outras palavras, na opinião daquelas pesquisadoras, ao invés de ponto de partida para a compreensão de que as letras representam valores sonoros relativamente estáveis, a escrita silábica é um resultado dessa compreensão.

Consistentemente com a sua hipótese, Cardoso-Martins e Batista (2005) observaram uma correlação estreita entre a incidência de escritas silábicas e a habilidade de escrever de modo semi-alfabético, isto é, de representar alguns sons na pronúncia da palavra por letras foneticamente apropriadas. Como nos exemplos citados anteriormente, as letras nas escritas silábicas das crianças que participaram do estudo de Cardoso-Martins e Batista correspondiam, em geral, às vogais ou então às consoantes cujo nome podia ser detectado na pronúncia da palavra (por exemplo, o nome das letras $Z \mathrm{e}$ $A$ na escrita ZA para a palavra zebra). Além disso, CardosoMartins e Batista observaram sinais claros de fonetização da escrita nas chamadas escritas pré-silábicas, isto é, escritas que não podem ser classificadas como silábicas e nem tampouco como alfabéticas. Em várias dessas escritas, a criança representava um único som corretamente, em geral o primeiro som consonantal ou vocálico na palavra. Quase sempre, esse som correspondia a um nome de letra na pronúncia da palavra. Como discutido por Cardoso-Martins e Batista, esses resultados fornecem apoio adicional para a hipótese de que as escritas silábicas resultam da compreensão incipiente da criança de que as letras representam sons particulares na pronúncia das palavras.

Essas observações sugerem que, ao invés dos estágios pré-silábico e silábico, uma descrição mais apropriada da evolução inicial da escrita consistiria em fases delimitadas, em grande parte, pela habilidade crescente da criança de representar sons na pronúncia da palavra por unidades ortográficas foneticamente apropriadas. Ehri $(1992,1998)$ apresenta uma descrição dessa natureza para o desenvolvimento da habilidade de ler e escrever palavras de crianças cuja língua materna é o inglês. De acordo com Ehri, as crianças progridem ao longo de quatro fases, cada qual caracterizada por um mecanismo dominante, embora de forma alguma exclusivo: 1) pré-alfabética; 2) semi-alfabética; 3) alfabética completa; e 4) alfabética consolidada.

Inicialmente, quando as crianças não conhecem o nome e os sons das letras, elas produzem letras mais ou menos arbitrárias, as quais não guardam qualquer relação com os sons na pronúncia das palavras. Na medida em que as crianças aprendem os nomes e os sons das letras, elas começam a compreender que as letras representam sons estáveis na pronúncia das palavras e começam a evidenciar essa compreensão nas suas escritas inventadas. Inicialmente, no entanto, elas só são capazes de representar alguns sons na pronúncia da palavra, geralmente um som no início ou no início e no final da pronúncia da palavra. Por exemplo, Ehri e Wilce (1985) citam o caso de uma criança que escreveu as letras JL para representar a palavra jail 'cadeia'. Como esse exemplo demonstra, os sons que as crianças são inicialmente capazes de representar correspondem freqüentemente a nomes de letras que podem ser detectados na pronúncia da palavra (ver também Levin, Patel, Kushnir \& Barad, 2002; Treiman, Tincoff \& Richmond-Welty, 1996; e Cardoso-Martins \& Batista, 2005, para evidência de que as crianças em idade pré-escolar usam o seu conhecimento do nome das letras para conectar a fala à escrita). Ehri chamou esse tipo de escrita de semi-alfabética para distingui-la do processamento alfabético completo característico da fase seguinte.

Para a maioria das crianças, a instrução explícita das correspondências entre os sons e as letras parece necessária para o início da fase alfabética completa. As crianças agora são capazes de representar todos os sons na pronúncia das palavras por letras foneticamente apropriadas. Na fase alfabética consolidada, as crianças passam a ser capazes de operar com unidades compostas por duas ou mais letras, as quais correspondem a sílabas ou partes de sílabas nas palavras. Um exemplo em inglês consiste na seqüência ight para representar o som /ait/ em palavras como light, fight e night.

Em uma série de estudos, Cardoso-Martins e seus colaboradores (ver Cardoso-Martins, 2005, para uma descrição desses estudos) mostraram que o modelo de fases de Ehri fornece uma descrição apropriada do desenvolvimento inicial da habilidade de leitura de palavras por crianças falantes do português do Brasil. Por exemplo, De Abreu e CardosoMartins (1998) mostraram que o conhecimento do nome das letras induz as crianças a aprender a ler por meio do processamento parcial das relações letra-som nas palavras. Seguindo o procedimento de Ehri e Wilce (1985), de Abreu e 
Cardoso-Martins submeteram crianças de 4 e 5 anos de idade a uma tarefa de aprendizagem de leitura que consistia de dois tipos de grafias simplificadas: grafias fonéticas, em que as letras correspondiam a sons na pronúncia da palavra (e.g., CRVA para a palavra "cerveja"), e grafias visuais, em que as letras não correspondiam a sons na pronúncia das palavras mas eram visualmente mais salientes (e.g., $\mathrm{X}_{\mathrm{OK}} \mathrm{O}$ para a palavra "cerveja"). Como previsto pela teoria de fases de Ehri, as crianças que conheciam os nomes das letras aprenderam a ler as grafias fonéticas mais facilmente do que as grafias visuais. Por outro lado, as crianças que ainda não conheciam os nomes das letras acharam as grafias visuais mais fáceis do que as grafias fonéticas. Resultados semelhantes foram encontrados para crianças com síndrome de Down (CardosoMartins, Michalick \& Pollo, 2006) e para adultos analfabetos (Cardoso-Martins, Rodrigues \& Ehri, 2003).

O presente estudo avalia a hipótese de que o modelo de Ehri também fornece uma descrição adequada do desenvolvimento inicial da escrita de crianças falantes do português. $\mathrm{O}$ estudo foi longitudinal e incluiu a participação de 20 crianças em idade pré-escolar. A habilidade das crianças de escrever palavras foi avaliada em intervalos de aproximadamente seis meses, por um período de dois anos. No início do estudo, as crianças ainda não haviam começado a ler e a maioria conhecia um número relativamente pequeno de letras. Ao final do estudo, por outro lado, praticamente todas as crianças já haviam começado a escrever alfabeticamente.

Com base nos resultados do estudo de Cardoso-Martins e Batista (2005), esperava-se que a seqüência de fases proposta por Ehri fornecesse uma descrição mais adequada das etapas iniciais do desenvolvimento da escrita do que o modelo de estágios de Ferreiro. Em particular, esperava-se que a fase semialfabética de Ehri fornecesse uma descrição mais apropriada das escritas que se convencionou chamar de silábicas.

\section{Método}

\section{Participantes}

Vinte crianças matriculadas em classes do primeiro período de uma escola particular de Belo Horizonte foram incluídas na amostra. No início do estudo, a idade das crianças variava entre 3 e 5 anos $(M=54,2$ meses, $D P=3,88)$. A última avaliação ocorreu quando as crianças estavam matriculadas no terceiro período da pré-escola, aproximadamente no final do primeiro semestre. Nessa ocasião, as crianças tinham, em média, 78,19 meses de idade $(D P=5,12)$.

\section{Procedimento}

A habilidade de escrever palavras foi avaliada em cinco ocasiões diferentes, separadas por intervalos de aproximadamente seis meses. O conhecimento do nome e dos sons das letras e a habilidade de leitura de palavras foram também avaliados em todas as ocasiões. As crianças foram avaliadas individualmente, em uma sala vazia na sua escola, em sessões que duravam em torno de 15 minutos. A habilidade de escrever palavras foi avaliada em duas sessões separadas, alguns dias após a avaliação do conhecimento das letras e da habilidade de leitura. As tarefas utilizadas são descritas a seguir.

\section{Instrumentos de medida}

Conhecimento do nome das letras. O examinador apresentava um cartão com as 24 letras do alfabeto dispostas em ordem aleatória e pedia para a criança nomear cada uma delas. Apenas letras maiúsculas foram utilizadas, uma vez que crianças em idade pré-escolar parecem ter mais familiaridade com letras maiúsculas do que com letras minúsculas (Ehri, 1986). A confiabilidade da tarefa, medida por meio do método de correlação entre as duas metades, variou entre 0,64 e $0,93(M=0,70, D=0,12)$.

Conhecimento dos sons das letras. A tarefa da criança consistia em identificar letras correspondendo a sons enunciados pelo examinador. O teste consistia de um item de treinamento e 15 itens experimentais. Dezesseis cartões, cada um contendo seis letras maiúsculas impressas em uma fileira horizontal no centro do cartão, foram confeccionados para a tarefa. Para cada item, o examinador apresentava o cartão correspondente, e pedia para a criança identificar a letra que "fazia" o som enunciado pelo examinador. Por exemplo, no primeiro ensaio, a criança via as letras R, M, F, P, D e $\mathrm{J}$, e devia indicar qual delas fazia o som /f/. As correlações entre as duas metades da tarefa variaram entre 0,41 e 0,77 $(M=0,61, D P=0,13)$.

Leitura de palavras. A tarefa avaliou a habilidade da criança de reconhecer 30 palavras (por exemplo, casa, mamãe, papai, gato, etc.) freqüentemente encontradas em livros para crianças (Pinheiro \& Keys, 1987). As palavras apareciam impressas em letras maiúsculas no centro de cartões individuais. Para cada cartão, a criança era instruída a ler a palavra impressa.

Nenhuma criança foi capaz de ler qualquer palavra na primeira avaliação e apenas uma havia começado a ler na segunda avaliação. As correlações entre as duas metades da tarefa nas três últimas ocasiões variaram entre 0,87 e 0,99 $(M=0,93, D P=0,06)$.

Escrita de palavras. A criança era solicitada a escrever uma série de palavras (20 palavras na primeira avaliação, 18 na segunda e 30 nas três últimas avaliações) da melhor maneira possível. Como pode ser visto no Anexo 1, apenas palavras comuns no vocabulário de crianças foram utilizadas para avaliar o desenvolvimento da escrita. Após a escrita de cada palavra, pedia-se para a criança lê-la em voz alta, passando o dedo sob a palavra escrita. Caso a criança dissesse que não sabia escrever uma palavra, dizíamos que não esperávamos que ela a escrevesse corretamente, mas apenas que ela tentasse escrever as letras que, segundo ela, eram necessárias para escrever a palavra.

Em todas as avaliações, metade das palavras foi ditada em um dia e metade no dia seguinte ou alguns dias depois, com o objetivo de não cansar a criança. Pela mesma razão, as duas primeiras avaliações, que ocorreram durante o primeiro ano da pré-escola, incluíram um número menor de palavras. Em todas as avaliações, as palavras variavam entre duas e quatro sílabas. Duas palavras de cinco sílabas também foram ditadas na quinta e última avaliação. Embora listas diferentes de palavras tenham sido utilizadas nas cinco avaliações, as listas não diferiam em relação à freqüência de ocorrência das palavras em livros para crianças, tomando como base a contagem de freqüência de palavras elaborada por Pinheiro 
e Keys (1987). Tampouco diferiam em relação ao número de nomes de letras que podiam ser detectados na pronúncia das palavras.

\section{Resultados}

\section{O desenvolvimento da escrita: o modelo de Emilia Ferreiro}

Para avaliar o desenvolvimento inicial da escrita segundo a teoria de Ferreiro, as escritas das crianças foram classificadas de acordo com três níveis diferentes: pré-silábico, silábico e alfabético. As escritas foram classificadas por dois juízes independentes. No caso de discordâncias, os dois juízes discutiam até chegarem a um acordo. Para cada uma das cinco ocasiões, uma criança era classificada em um dos três níveis quando mais da metade das suas escritas correspondia a escritas daquele nível. Em casos de empate entre dois níveis, a criança era classificada no nível menos avançado. Os três níveis são descritos a seguir.

O nível pré-silábico consistia de escritas que não apresentavam nenhum tipo de correspondência letra-sílaba ou letra-som. Exemplos incluem APHJM para queijo e DLLEB para girafa.

O nível silábico consistia de escritas em que o número de letras correspondia ao número de sílabas na palavra. As escritas AEM para girafa, TICA para telefone e $F Q$ para figo são exemplos de escritas classificadas como silábicas.

As escritas alfabéticas eram escritas em que todos os sons na pronúncia da palavra eram representados por uma letra foneticamente apropriada, mesmo que convencionalmente incorreta. Esse era o caso da escrita GIPI parajipe. Escritas semialfabéticas em que o número de sons representados por uma letra foneticamente apropriada, mesmo que convencionalmente incorreta, era superior ao número de sons não representados ou representados inapropriadamente (por exemplo, VIA para veia, GIRAGOU para girassol, ou ainda QEIO para queijo) foram também incluídas nesse nível. A razão para isso resultou do fato de que a frequiência desse tipo de escrita foi relativamente pequena, não justificando uma categorização própria, intermediária entre a escrita silábica e a escrita alfabética. Uma letra foi considerada foneticamente apropriada caso representasse o som em questão em outras palavras da língua portuguesa, mesmo que apenas em outros contextos ortográficos. Por exemplo, a letra $U$ no final da escrita GIRAGOU foi considerada foneticamente apropriada uma vez que ela representa o som $/ \mathrm{w} / \mathrm{em}$ palavras como pau e chapéu, por exemplo. Trocas de letras - como, por exemplo, o uso da letra $c$ ou $q$ para representar o fonema/g/ (ou o uso da letra $g$ para representar o fonema $/ \mathrm{k} /$ ) foram consideradas foneticamente apropriadas. Em todos os casos, a troca envolvia sons que diferem apenas em relação ao traço da sonorização. Esse é o caso das consoantes $/ \mathrm{k} / \mathrm{e} / \mathrm{g} /$. Ambas são semelhantes no que diz respeito ao modo e ao ponto da articulação, diferindo apenas em relação à vibração (sonorização) das cordas vocais quando $\mathrm{o}$ ar passa pela laringe.

A Figura 1 descreve o número de crianças classificadas em cada um dos três níveis, separadamente para cada avaliação. A figura também ilustra as mudanças que ocorreram entre uma avaliação e outra. As setas horizontais indicam o número de crianças que permaneceram no mesmo nível, enquanto as setas diagonais indicam o número de crianças que mudaram de nível de uma avaliação para outra. As setas descendentes representam mudanças para níveis mais avançados; as setas ascendentes, por outro lado, indicam regressões, ou seja, mudanças para níveis menos avançados de escrita.

Apenas sete crianças foram classificadas como silábicas ao longo de todo o estudo (uma criança foi classificada como silábica em duas ocasiões diferentes e seis em apenas uma das cinco ocasiões). A maioria das crianças aparentemente "pulou" o estágio silábico, isto é, passou diretamente do nível pré-silábico para o nível alfabético. Esses resultados questionam a hipótese de que o estágio silábico consiste em um estágio universal no desenvolvimento da escrita. Com efeito, apesar de apenas sete crianças terem apresentado evidência consistente com esse tipo de escrita, salvo uma única criança, todas foram capazes de escrever alfabeticamente no final do estudo.

\section{O desenvolvimento da escrita: o modelo de fases de Linnea Ehri}

A Figura 2 ilustra os resultados de acordo com os três primeiros níveis do desenvolvimento da escrita sugeridos pelo modelo de Ehri: pré-alfabético, semi-alfabético e alfabético. O nível alfabético-consolidado não foi considerado, tendo em vista que, nem mesmo na última avaliação, as crianças deram mostras de possuir um conhecimento consolidado da ortografia. O nível alfabético é idêntico ao último nível no modelo de Ferreiro e não será descrito novamente. Como nas análises descritas anteriormente, uma criança foi designada para cada um desses níveis quando mais da metade de suas escritas havia sido classificada naquele nível. Em casos em que esse critério não podia ser utilizado, a criança foi designada para o nível contendo o maior número de escritas. Uma exceção a essa regra ocorreu em casos em que, embora a criança tivesse produzido um número maior de escritas pré-alfabéticas do que de escritas semi-alfabéticas ou alfabéticas, a soma desses dois tipos de escritas era superior ao número de escritas pré-alfabéticas. Por exemplo, uma criança produziu 14 escritas pré-alfabéticas, 11 escritas semi-alfabéticas e cinco escritas alfabéticas na quarta avaliação. Em casos como esse, a criança foi designada para o nível semi-alfabético. Finalmente, em casos em que metade das escritas havia sido classificada em um nível e metade em outro, a criança era designada para o nível menos avançado.

O nível pré-alfabético consistia de escritas em que as letras não guardavam qualquer relação com os sons na pronúncia das palavras. Exemplos incluem DLLEB para girafa ou VIOBORPOD para cabelo.

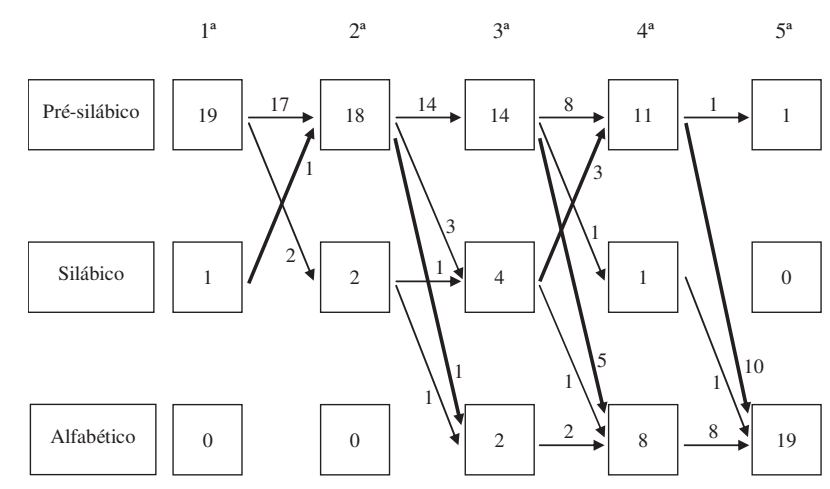

Figura1. O desenvolvimento da escrita segundo o modelo de Ferreiro. 


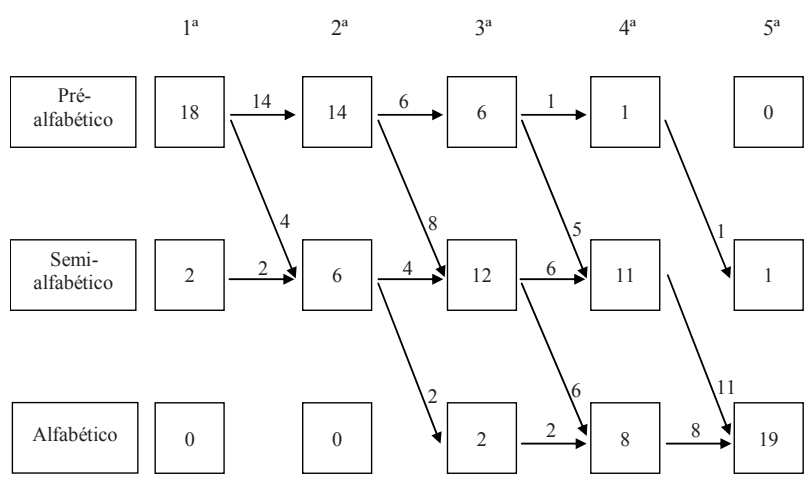

Figura 2. O desenvolvimento da escrita segundo o modelo de Ehri.

As escritas semi-alfabéticas consistiam de escritas em que a letra inicial representava a primeira consoante ou vogal na palavra de maneira foneticamente apropriada (por exemplo, TAP para telefone, IADCHJ para chicote e VPRADTJI para veia). Apenas a primeira letra na escrita da palavra foi levada em consideração, tendo em vista a evidência de que crianças em idade pré-escolar prestam mais atenção às relações letra-som no início das palavras. Por exemplo, no estudo mencionado anteriormente, de Abreu e Cardoso-Martins (1998) pediram para as crianças escrever as grafias fonéticas e visuais que haviam aprendido. As crianças que não conheciam os nomes das letras se saíram muito mal, tanto no caso das grafias fonéticas quanto no caso das grafias visuais. Por outro lado, as crianças que conheciam os nomes das letras lembraram um número maior de letras para as escritas fonéticas do que para as escritas visuais. No entanto, na imensa maioria dos casos, apenas a letra inicial das grafias fonéticas foi reproduzida corretamente.

Conforme pode ser visto na Figura 2, o modelo de fases de Ehri parece oferecer uma descrição mais adequada do desenvolvimento inicial da escrita em português do que o modelo de estágios de Ferreiro. Em particular, o nível semi-alfabético apareceu como um nível intermediário entre o nível pré-alfabético e o nível alfabético para 19 das 20 crianças cuja escrita, classificada como pré-alfabética na primeira avaliação, apresentou evolução ao longo do estudo. Nenhuma criança pareceu 'pular' o nível semi-alfabético, passando diretamente do nível pré-alfabético para o nível alfabético. Por outro lado, na classificação segundo o modelo de estágios de Ferreiro, 13 crianças progrediram diretamente do nível pré-silábico para o nível alfabético. Além disso, como pode ser visto na Figura 1, quatro das sete crianças classificadas como silábicas regrediram do nível silábico para o nível pré-silábico antes de progredirem para o nível alfabético, fato difícil de ser acomodado por um modelo de estágios.

\section{Qual é a natureza da escrita silábica?}

A Tabela 1 apresenta a proporção média de escritas silábicas e de respostas corretas nas tarefas de leitura e conhecimento de letras, separadamente para cada avaliação. Como ilustrado nessa tabela, as escritas silábicas ocorreram muito infreqüentemente nas duas primeiras ocasiões, quando as crianças conheciam um número relativamente pequeno de letras. As escritas silábicas foram mais freqüentes na terceira avaliação, precisamente a ocasião em que as crianças revelaram conhecer mais da metade dos nomes das letras, embora ainda não tivessem começado a escrever alfabeticamente.
Tabela 1. Proporção média (e desvio padrão) de escritas silábicas e de respostas corretas nas tarefas de conhecimento das letras e de leitura de palavras em função da avaliação.

\begin{tabular}{llccc}
\hline \multirow{2}{*}{ Avaliação } & $\begin{array}{l}\text { Escritas } \\
\text { silábicas }\end{array}$ & $\begin{array}{c}\text { Nome das } \\
\text { letras }\end{array}$ & $\begin{array}{c}\text { Som das } \\
\text { letras }\end{array}$ & $\begin{array}{c}\text { Leitura de } \\
\text { palavras }\end{array}$ \\
\hline $1^{\underline{a}}$ & $0,13(0,19)$ & $0,31(0,26)$ & $0,27(0,21)$ & \\
$2^{\underline{a}}$ & $0,19(0,27)$ & $0,48(0,28)$ & $0,33(0,20)$ & $0,01(0,03)$ \\
$3^{\text {a }}$ & $0,34(0,27)$ & $0,72(0,25)$ & $0,48(0,27)$ & $0,04(0,11)$ \\
$4^{\text {a }}$ & $0,19(0,20)$ & $0,92(0,09)$ & $0,73(0,22)$ & $0,20(0,31)$ \\
$5^{\text {a }}$ & $0,01(0,04)$ & $0,98(0,04)$ & $0,93(0,06)$ & $0,50(0,39)$ \\
\hline
\end{tabular}

Esses resultados são consistentes com a sugestão de Cardoso-Martins e Batista (2005) de que a escrita silábica resulta da tendência da criança pequena de escrever as letras cujos nomes ela é capaz de detectar na pronúncia da escrita. $\mathrm{Na}$ medida em que isso é verdade, a freqüência de escritas silábicas deveria correlacionar-se estreitamente com a habilidade incipiente da criança de representar relações letra-som em suas escritas. Três análises foram realizadas para avaliar essa hipótese. Em primeiro lugar, avaliou-se se as crianças classificadas como silábicas, de acordo com o modelo de Ferreiro, haviam sido classificadas como semi-alfabéticas no modelo de Ehri. Dos oito casos classificados como silábicos, apenas um foi classificado como pré-alfabético. Todos os demais foram classificados como semi-alfabéticos, uma diferença significativa pelo teste binomial unilateral, $p<0,05$.

Em segundo lugar, calculou-se o número médio de escritas silábicas para as crianças classificadas como pré-alfabéticas e semi-alfabéticas, separadamente para a segunda e para a terceira avaliação. Apenas duas crianças foram classificadas como semi-alfabéticas na primeira avaliação e apenas uma foi classificada como pré-alfabética na quarta avaliação. Na quinta e última avaliação, com exceção de uma criança, todas foram classificadas como alfabéticas. Como pode ser visto na Tabela 2, as crianças classificadas como semi-alfabéticas produziram um número maior de escritas silábicas do que as crianças classificadas como pré-alfabéticas em ambas as avaliações. Com efeito, a diferença entre os dois grupos foi estatisticamente significativa na terceira avaliação, $t(16)=-2,27, p<0,01$, unilateral.

Tabela 2. Proporção média (e desvio padrão) de escritas silábicas produzidas pelas crianças pré-alfabéticas e semi-alfabéticas na $2^{\mathrm{a}}$ e na $3^{\mathrm{a}}$ avaliação.

\begin{tabular}{lcc}
\hline \multirow{2}{*}{ Avaliação } & \multicolumn{2}{c}{ Nível de escrita } \\
\cline { 2 - 3 } & Pré-alfabética & Semi-alfabética \\
\hline $2^{\mathrm{a}}$ & $0,11(0,15)$ & $0,36(0,41)$ \\
$3^{\mathrm{a}}$ & $0,20(0,12)$ & $0,46(0,27)$ \\
\hline
\end{tabular}

Finalmente, todas as letras nas escritas silábicas das crianças classificadas como silábicas foram codificadas como foneticamente apropriadas ou arbitrárias. Uma letra foi codificada como arbitrária caso ela não apresentasse qualquer relação com um som na sílaba em questão. Por exemplo, na escrita $A E J$ para a palavra laranja, a letra $e$, que presumivelmente representa a segunda sílaba na palavra foi codificada 
como arbitrária, uma vez que o som que essa letra tipicamente representa não pode ser detectado na pronúncia da sílaba /rã/. As letras foneticamente apropriadas foram classificadas como "nome de letra" ou como "som de letra". No primeiro caso, o nome inteiro da letra podia ser detectado na pronúncia da palavra (por exemplo, a letra $a$ que aparece no início da escrita $A E J$, para laranja, foi classificada como nome de letra, uma vez que o seu nome, i.e., /a/ é claramente audível no início da pronúncia da palavra). As demais letras foram classificadas como som de letra. Em praticamente todos os casos, as letras classificadas como som de letra representavam um fonema contido no nome da letra (por exemplo, a letra $j$ na escrita $A E J$, para laranja, parece representar o fonema $/ \mathrm{j} /$, o qual pode ser detectado no nome da letra $j$ ).

Em conformidade com a hipótese de uma forte associação entre a escrita silábica e a fonetização da escrita, a maioria das letras nas escritas silábicas consistiu de letras foneticamente apropriadas (Proporção média=0,69). De fato, com exceção de uma única criança, todas as crianças classificadas como silábicas produziram um número maior de letras fonéticas do que de letras arbitrárias em suas escritas silábicas, uma diferença estatisticamente significativa de acordo com o teste binomial unilateral, $p<0,05$. Como pode ser visto na Tabela 3, a maioria das letras fonéticas nas escritas silábicas daquelas crianças eram letras cujos nomes podiam ser claramente detectados na pronúncia das palavras.

Tabela 3. Proporção média (e desvio padrão) de letras fonéticas codificadas como nome ou som de letra nas escritas silábicas das crianças silábicas.

\begin{tabular}{lclc}
\hline \multicolumn{2}{c}{ Nome de letra } & \multicolumn{2}{c}{ Som de letra } \\
\hline Consoante & Vogal & Consoante & Vogal \\
\hline $0,10(0,06)$ & $0,59(0,16)$ & $0,21(0,16)$ & $0,09(0,14)$ \\
\hline
\end{tabular}

\section{Discussão}

O presente estudo investigou a hipótese de que o modelo de fases de Ehri oferece uma descrição mais adequada das fases iniciais do desenvolvimento da escrita e, em particular, das chamadas escritas silábicas, do que o modelo de Ferreiro. Conforme se observou anteriormente, Ferreiro (1989, 1990; Ferreiro \& Teberosky, 1986) tem argumentado que as escritas silábicas resultam da busca pela criança por um critério geral que lhe permita regular o número de letras necessárias para escrever palavras diferentes. Como resultado dessa busca, a criança elabora a hipótese de que as letras representam sílabas inteiras na pronúncia das palavras. Um aspecto importante do argumento de Ferreiro é que a hipótese silábica independe do conhecimento do nome e dos sons das letras. De fato, Ferreiro e Teberosky (1986) argumentam que as escritas silábicas são observadas até mesmo entre crianças que não conhecem as letras do alfabeto e, como resultado, produzem pequenos círculos ou traços quando solicitadas a escrever da melhor maneira possível.

Ao contrário de Ferreiro, Ehri (1992, 1998; Ehri \& Wilce, 1985) tem argumentado que o conhecimento do nome e dos sons das letras é crucial para a compreensão de que a escrita representa a fala. Com efeito, Ehri apresenta evidência de que a primeira manifestação dessa compreensão consiste de escritas que representam sons na pronúncia das palavras por letras foneticamente apropriadas. Inicialmente, no entanto, os sons que a criança é capaz de representar correspondem freqüentemente a nomes de letras na pronúncia das palavras. Conforme é discutido a seguir, os resultados do presente estudo sugerem que essas características da escrita da criança em idade pré-escolar oferecem uma explicação mais parcimoniosa para as chamadas escritas silábicas do que a explicação conceitual de Ferreiro.

Não foi encontrada praticamente nenhuma evidência de que as crianças prestam atenção apenas à dimensão quantitativa quando escrevem silabicamente. Conforme descrevemos anteriormente, a imensa maioria das letras nas escritas silábicas das crianças designadas para o estágio silábico consistia de letras foneticamente apropriadas. Em vários casos (e.g., $C V A$ para cerveja, ZA para zebra, DU para dedo, $A U$ para dado, AAA para barata, IIEA para bicicleta, AAUA para tartaruga, GAIA para gelatina, etc.), os nomes de todas as letras na escrita da criança podiam ser claramente detectados na pronúncia da palavra.

Além disso, ao contrário da sugestão de Ferreiro de que a hipótese silábica consiste na primeira manifestação da compreensão de que a escrita representa a fala e, como tal, constitui um marco importante no desenvolvimento da escrita, um número relativamente grande de crianças classificadas como pré-silábicas segundo o modelo de Ferreiro foram classificadas como semi-alfabéticas segundo o modelo de Ehri. Por exemplo, $91 \%$ das crianças classificadas como pré-silábicas na quarta avaliação foram capazes de representar sons no começo das palavras por letras foneticamente apropriadas. Juntamente com a evidência discutida anteriormente, esses resultados sugerem que, ao invés de uma construção conceitual, a escrita silábica é mais adequadamente descrita como um resultado da compreensão da criança de que as letras correspondem a sons na pronúncia da palavra.

Essa explicação é capaz de acomodar o número surpreendentemente pequeno de escritas silábicas observadas no presente estudo. De fato, enquanto o estágio silábico apareceu como um estágio intermediário entre o estágio pré-silábico e o estágio alfabético em apenas $15 \%$ das crianças, $95 \%$ delas passaram pela fase semi-alfabética em sua progressão para a fase alfabética.

O modelo de Ehri parece, portanto, oferecer uma explicação mais parcimoniosa do desenvolvimento inicial da escrita do que o modelo de Ferreiro. De fato, enquanto o modelo de Ehri parece capaz de acomodar dados de línguas tão diversas como o inglês e o português do Brasil, a evidência em favor de um estágio silábico provém apenas de observações de crianças falantes de línguas latinas. Ferreiro (1990) sugeriu que o número pequeno de escritas silábicas observado entre crianças de língua inglesa pode ser explicado em termos da incidência relativamente pequena de palavras multissilábicas na língua inglesa. Presumivelmente, essa característica impediria a criança falante do inglês de explorar a hipótese silábica. É possível, no entanto, que a ausência de escritas silábicas entre essas crianças resulte do fato de que, em inglês, um número relativamente pequeno de sons vocálicos corresponde a nomes de letras (Cardoso-Martins, Resende \& Rodrigues, 2002).

É pouco provável que os resultados do presente estudo e, em particular, o número relativamente pequeno de escritas 
silábicas ou de crianças classificadas como silábicas, possam ser explicados em termos de alguma característica idiossincrática das crianças que participaram do presente estudo. É possível, não obstante, que um número maior de escritas silábicas tivesse sido observado caso houvéssemos avaliado as crianças mais freqüentemente. No estudo em questão, o intervalo entre as avaliações foi de aproximadamente seis meses. Avaliações recorrentes e com intervalos de tempo menores poderiam favorecer a observação de escritas silábicas. Essa possibilidade está sendo avaliada em um estudo em andamento no nosso laboratório na Universidade Federal de Minas Gerais.

Parte do apelo da teoria de Ferreiro tem a ver com a sua visão da criança como um ser ativo, que formula e testa hipóteses a respeito da escrita e de outros objetos do conhecimento. O modelo de fases de Ehri é perfeitamente compatível com essa visão. Com efeito, esse modelo baseia-se na observação de que a criança em idade pré-escolar explora ativamente o seu conhecimento do nome e dos sons das letras na tentativa de compreender a natureza da escrita.

Em suma, os resultados do presente estudo questionam a universalidade de um estágio silábico (Ferreiro, 1989, 1990; Ferreiro \& Teberosky, 1986) no desenvolvimento da escrita nos anos pré-escolares. Ao invés disso, nossos resultados sugerem que o desenvolvimento da escrita em português é mais adequadamente descrito em termos da habilidade crescente da criança de detectar segmentos fonológicos na pronúncia das palavras e de conectar esses segmentos a segmentos ortográficos apropriados. Os resultados do nosso estudo sugerem que o modelo de fases de Ehri (1992, 1998), formulado com base em observações do desenvolvimento da leitura e da escrita em inglês, pode ser proveitosamente estendido para o desenvolvimento da escrita em sistemas de escrita mais transparentes, isto é, sistemas em que as correspondências letra-som são mais consistentes ou regulares, do que o inglês.

\section{Referências}

Cardoso-Martins, C., Resende, S. M. \& Rodrigues, L. A. (2002). Letter name knowledge and the ability to learn to read by processing letterphoneme relations in words: Evidence from Brazilian Portuguesespeaking children. Reading and Writing, 15, 409-432.

Cardoso-Martins, C., Rodrigues, L. A. \& Ehri, L. C. (2003). Place of environmental print in reading development: Evidence from nonliterate adults. Scientific Studies of Reading, 7, 335-355.

Cardoso-Martins, C. (2005). Beginning reading acquisition in Portuguese. Em M. Joshi (Org.), Handbook of orthography and literacy (pp.171-187). Mahwah: Erlbaum.

Cardoso-Martins, C. \& Batista, A.C. E. (2005). O conhecimento do nome das letras e o desenvolvimento da escrita: Evidência de crianças falantes do português. Psicologia: Reflexão \& Crítica, 18(3), 330-336.

Cardoso-Martins, C., Michalick, M. F. \& Pollo, T. C. (2006). O papel do conhecimento do nome das letras no início da aprendizagem da leitura: evidência de indivíduos com síndrome de Down. Psicologia: Reflexão e Crítica, 19(1), 53-59.

Comissão de Educação e Cultura da Câmara dos Deputados (2003). Alfabetização Infantil: Os novos caminhos. Relatório final. Brasília, DF.
De Abreu, M. \& Cardoso-Martins, C. (1998). Alphabetic access route in beginning reading acquisition in Portuguese: The role of letter-name knowledge. Reading and Writing: An Interdisciplinary Journal, 10(2), 85-104.

Ehri, L. (1986). Sources of difficulty in learning to spell and read. Em M. Wolraich \& D. Routh (Orgs.), Advances in developmental and behavioral pediatrics (pp. 121-195). Greenwich: JAI Press.

Ehri, L. (1992). Reconceptualizing the development of sight word reading and its relationship to recoding. Em P. Gough, L. Ehri \& R. Treiman (Orgs.), Reading acquisition (pp. 107-143). Hillsdale: Erlbaum.

Ehri, L. (1998). Learning to read and learning to spell are one and the same, almost. Em C. Perfetti, L. Rieben \& M. Fayol (Orgs.), Learning to spell: Research, theory, and practice across languages (pp. 237-269). Mahwah: Erlbaum.

Ehri, L. \& Wilce, L. (1985). Movement into reading: Is the first stage of printed word learning visual or phonetic? Reading Research Quarterly, 20(2), 163-179.

Ferreiro, E. (1989). Reflexões sobre a alfabetização. São Paulo: Cortez.

Ferreiro, E. (1990). Literacy development: Psychogenesis. Em Y. M. Goodman (Org.), How children construct literacy: Piagetian perspectives (pp. 12-25). Newark: International Reading Association.

Ferreiro, E. \& Gomez Palacio, M. (1982). Analisis de las perturbaciones en el proceso de aprendizaje escolar de la lectura y de la escritura. México: Siglo XXI.

Ferreiro, E. \& Teberosky, A. (1986). Psicogênese da língua escrita. São Paulo: Artes Médicas.

Grossi, E. P. (1990). Applying psychogenesis principles to the literacy instruction of lower-class children in Brazil. Em Y. M. Goodman (Org.), How children construct literacy: Piagetian perspectives (pp. 99-114). Newark: International Reading Association.

Levin, I., Patel, S., Kushnir, T. \& Barad, N. (2002). Letter names: Effect on letter saying, spelling, and word recognition in Hebrew. Applied Psycholinguistics, 23(2), 269-300.

Pimentel, M. A. M. (1986). Alfabetização: a construção do objeto conceitual. Educação em Revista, 3, 39-50.

Pinheiro, A. M. V. \& Keys, K. (1987). A word frequency count in Brazilian Portuguese. Manuscrito não publicado, University of Dundee, Dundee, Escócia.

Pontecorvo, C. \& Zucchermaglio, C. (1990). A passage to literacy: Learning in a social context. Em Y. M. Goodman (Org.), How children construct literacy: Piagetian perspectives (pp. 59-98). Newark: International Reading Association.

Silva, F. S. \& Farias, M. C. Q. (2003). Linguagem na educação infantil. Fortaleza: SEDUC.

Treiman, R., Tincoff, R. \& Richmond-Welty, D. (1996). Letter names help children connect print and speech. Developmental Psychology, 32(3), 505-514.

Recebido em 23.11.2006

Primeira decisão editorial em 09.10.2007

Versão final em 12.11.2007

Aceito em 11.08.2008 
Anexo 1. Itens da tarefa de escrita de palavras separadamente para cada avaliação.

\begin{tabular}{|c|c|c|c|c|}
\hline Primeira & Segunda & Terceira & Quarta & Quinta \\
\hline Zebra & Queijo & Queijo & Quibe & Quilômetro \\
\hline Piano & Sino & Salsicha & Gelatina & Gelado \\
\hline Xerife & Cabelo & Canivete & Rinoceronte & Rinoceronte \\
\hline Beterraba & Bicicleta & Bicicleta & Chiclete & Chiqueiro \\
\hline Esquilo & Galo & Dedo & Tomada & Taça \\
\hline Cerveja & Sereia & Chicote & Bigode & Baile \\
\hline Girafa & Beijo & Laranja & Zebu & Zebu \\
\hline Dedo & Pipa & Veia & Jipe & Jarro \\
\hline Sirene & Quiabo & Mandioca & Verruga & Veludo \\
\hline Tartaruga & Pêlo & Faca & Salame & Sirene \\
\hline Cavalo & Girafa & Girassol & Degrau & Detetive \\
\hline Xícara & Dedo & Riacho & Microfone & Miolo \\
\hline Pescoço & Tartaruga & Tartaruga & Caramelo & Caramujo \\
\hline Cigarro & Gelado & Zebra & Filhote & Fivela \\
\hline Bicicleta & Dado & Jipe & Lapiseira & Laranjada \\
\hline Chefe & Telefone & Zorro & Jóia & Jóia \\
\hline Gelado & Gelo & Beijo & Beterraba & Berço \\
\hline Doce & Coqueiro & Coqueiro & Zangão & Zorro \\
\hline Isqueiro & & Geladeira & Vasilha & Vacina \\
\hline \multirow[t]{11}{*}{ Zorro } & & Limão & Jabuticaba & Gilete \\
\hline & & Xarope & Cemitério & Cegonha \\
\hline & & Dado & Queijo & Querosene \\
\hline & & Quiabo & Diamante & Dinossauro \\
\hline & & Rapadura & Merenda & Mariposa \\
\hline & & Cereja & Raquete & Rapadura \\
\hline & & Jóia & Feijoada & Farofa \\
\hline & & Miolo & Limonada & Limonada \\
\hline & & Vacina & Churrasco & Chupeta \\
\hline & & Telefone & Cocada & Cotonete \\
\hline & & Figo & Teclado & Telha \\
\hline
\end{tabular}

